\title{
A importância de atividades de empoderamento feminino como forma de minimizar a evasão das mulheres nos cursos de Tecnologia da Informação
}

\author{
Thalia S. Santana ${ }^{1}$, Ianka T. B. Assis ${ }^{1}$, Ramayane B. Braga ${ }^{1}$, Natália C. Louzada ${ }^{1}$ \\ ${ }^{1}$ Instituto Federal Goiano - Campus Ceres (IF GOIANO) \\ Caixa Postal 51 - 76.300-000 - Ceres - GO - Brasil \\ \{thaliassantana15, iankatalitaa\}@gmail.com, \\ \{ramayane.santos, natalia.louzada\}@ifgoiano.edu.br
}

\begin{abstract}
The objective of this research is to highlight activities of female empowerment applied in an extension project, this as an incentive for students in high school, technical and higher education to remain in the area of computing. Activities such as emphasizing female representation in computer history, discussion of concepts of feminism and gender, training in fields of increasing TI development, do parts of strategies for minimize the evident evasion of women in this occupation area.
\end{abstract}

Resumo. O objetivo do estudo é destacar atividades de empoderamento feminino aplicadas através de um projeto de extensão, como incentivo às estudantes dos cursos de ensino médio, técnico e superior a permanecerem na área da computação. Atividades como enfatização da representação feminina na história da informática, discussão sobre conceitos de feminismo e gênero, capacitação em campos de crescente desenvolvimento em TI, são parte das estratégias para minimizar a evidente evasão das mulheres nesse ramo.

\section{Introdução}

A desproporcionalidade entre homens e mulheres nos ramos de ciência e tecnologia $(\mathrm{C} \& \mathrm{~T})$ é considerada evidente entre os pesquisadores da área. Há vários fatores responsáveis pelo número inferior de mulheres neste campo, sejam socioculturais, econômicos, educativos (SOARES, 2001). Estes, contudo, ainda são de difícil compreensão em nossa sociedade que, muitas vezes, recorre a estereótipos ao se referir à relação profissional e intelectual de mulheres com a informática.

Segundo Schiebinger (2001, p.37) "a ciência moderna é um produto de centenas de anos de exclusão das mulheres, o processo de trazer mulheres para a ciência exigiu, e vai continuar a exigir, profundas mudanças estruturais na cultura, métodos e conteúdo da ciência". A exemplo disso, apenas no ano de 1913 a participação de mulheres na ciência se tornou objeto de escrita e, no Brasil, estudos significativos a esse respeito foram realizados apenas em 1998 e posteriormente, em 2003. Deste modo, assim como acontece na ciência de maneira geral, na informática, tida como área afim ou subárea da ciência, também não são perceptíveis as ações femininas (SCHWARTZ et al., 2006).

Nosso país possui um histórico de industrialização recente e, portanto, C \& T são áreas igualmente recentes - já que acompanham o processo industrial. Contudo, 
além da pequena presença de mulheres nas áreas profissionais de informática, é igualmente nítido o fato de que a invisibilização e exclusão tácitas das mulheres nesta área vêm transformando historicamente o campo da tecnologia numa "escolha" quase exclusivamente masculina. Causando uma naturalização das relações sociais de gênero existentes no âmbito da atuação profissional em informática e tecnologia (LETA, 2003).

De acordo com o Programa Internacional de Avaliação de Alunos - PISA (2015), apenas 5\% das meninas que possuem expectativas profissionais seguem por áreas de engenharia ou mesmo, computação. Um dos apontamentos deste estudo sugere que a falta de confiança atribuída ao "pensar cientificamente" possui correlação com o gênero dos estudantes. Entre as meninas há uma maior falta de confiança e menor desempenho, entretanto, segundo este estudo, quando meninos e meninas são igualmente confiantes, a diferença de desempenho em matemática por exemplo, é visivelmente reduzida.

Sendo assim, é perceptível a falta de reconhecimento de alguns aspectos importantes - relacionados à ausência de interesse das mulheres pela área. Segundo Schwartz et al. (2006), Sales et al. (2014) e Castro (2013), desde a escassez de exemplos femininos a serem seguidos, poucas informações sobre oportunidades de crescimento de carreira até temas polêmicos, como paridade salarial, assédio e preconceito, são coeficientes que caracterizam o afastamento feminino da computação. Deste modo, atividades de incentivo a meninas e mulheres possibilitam considerável diminuição da evasão dos cursos de Tecnologia da Informação (TI).

\section{Iniciativas de empoderamento}

De acordo com Bertrand Russel et al. (1979), poder se relaciona à capacidade de suprir desejos, vontades, objetivos, ainda que contra resistências de quaisquer natureza. Nesse sentido, empoderamento, tal como aqui empregamos, significa o acesso à recursos de capacitação, autoestima e pró-atividade que permitam a indivíduos ou grupos conquistar maior poder em diferentes âmbitos: social, econômico, político, cultural. Empoderar, por conseguinte, constitui no processo de construção da autonomia objetivando a transformação da realidade em que sujeitos e grupos estão inseridos.

Conforme Schwartz et al. (2006), no que se refere à área de informática, ainda que inúmeras pioneiras sejam reconhecidas como parte importante da história deste campo científico, tais como Augusta Ada Byron e Grace Murray Hopper, a relevância da atuação feminina para a evolução tecnológica vem sendo negligenciada e mesmo omitida, o que contribui para a delimitação das áreas de atuação profisssional ligadas à informática como atividades supostamente masculinas.

Por isso, a significativa evasão feminina em cursos de nível médio, técnico e superior ligados a esta área; além da reduzida quantidade de mulheres em carreiras científicas no Brasil, tornam as iniciativas de empoderamento e inserção femininas, parte de estratégias importantes para a equalização das relações de gênero neste campo.

As referidas ações podem ser diversas, adotando as mais diferentes metodologias de sensibilização e formação. A tabela abaixo (Tabela 1) aponta atividades já desenvolvidas ou a serem realizadas, que identificamos como profícuas para o empoderamento feminino no campo da informática, combatendo a evasão escolar. 
Tabela 1. Propostas de atividades do projeto em desenvolvimento

\begin{tabular}{|c|l|}
\hline Análise e compreensão & $\begin{array}{l}\text { Organização de ciclo de debates, mesas redondas e discussões } \\
\text { abordando "relações de gênero e protagonismo feminino na } \\
\text { computação"; painéis e murais de caráter informativo; estudos das reais } \\
\text { situações de exclusão e desestímulo }\end{array}$ \\
\hline Conscientização & $\begin{array}{l}\text { Palestras, mostra de filmes para promoção de informação; contato com } \\
\text { perfis e perspectivas de dificuldade e êxito }\end{array}$ \\
\hline Capacitação e aproximação & $\begin{array}{l}\text { Organização/participação de oficinas e workshops, além de visitas } \\
\text { técnicas em prol de qualificação e viabilização das estudantes e contato } \\
\text { com profissionais de sucesso; aproximação de áreas e temáticas; } \\
\text { enquetes afetivas relacionadas ao cotidiano de estudo e trabalho das } \\
\text { mulheres na área de informática }\end{array}$ \\
\hline Produção & $\begin{array}{l}\text { Catalogação de produtos e materiais de empoderamento (vídeos, } \\
\text { fanzines, aplicativos, etc); criação de um coletivo de estudos e ações }\end{array}$ \\
\hline
\end{tabular}

A exemplo dessas iniciativas, a realização de uma palestra recontando essa história com ênfase na participação feminina através da visão de uma profissional de informática, nos proporcionou um feedback positivo de estudantes, que, em sua maioria, não conheciam boa parte dessa história. Tais meninas também não possuíam conhecimento quanto a notoriedade da participação feminina na história da tecnologia, eventualmente poderiam obter tal conhecimento como forma de incentivo às futuras estudantes dos cursos de TI.

Em contexto semelhantes a esse, a identificação das representações sociais que compõem o imaginário estudantil acerca de mulheres que estudam e atuam profissionalmente nesse campo pode ser outro caminho interessante, investigando uma possível correlação entre estereótipos de gênero em informática, evasão escolar e desestímulo à atuação profissional feminina. Vale ressaltar que no ambiente aplicado, antes deste, não havia nenhum meio de discussão e desmistificação, fazendo com que as atividades tenham atraído um público bastante sensibilizado e ausente de informações.

No âmbito das atividades desenvolvidas pelas autoras, após a realização de um questionamento com alunas do ensino médio, identificou-se a existência de um sentimento de insegurança com relação a permanência e possível ingresso em cursos superiores em TI, inclusive por falta de capacitação em áreas específicas. Em outra ocasião foi idealizado um bate-papo pelas autoras num shopping center como forma de diagnosticar a situação escolar com base no gênero dos estudantes, também constatou-se que, mesmo possuindo interesse pela área, muitas meninas sentem-se intimidadas por ideias preconcebidas, tais como: "informática é muito difícil", ou “informática é uma atividade mais para homens", visto que também no contexto imerso, a representatividade é expressa por apenas duas mulheres como professoras no ramo, em meio a cursos de nível médio e superior.

Portanto, com intuito de lidar com tais situações as autoras elaboraram esse projeto a partir das sugestões da SBC - Sociedade Brasileira da Computação - e dos Princípios de Empoderamento da ONU Mulheres, com o objetivo de proporcionar oficinas e palestras para capacitação e desenvolvimento profissional das meninas da 
instituição educacional em que atuam. Discutindo questões de gênero e feminismo, além de oferecer às estudantes a formação político-filosófica necessária para questionar preconceitos e transformar a realidade social em que se inserem.

Ademais, para que as iniciativas de empoderamento sejam bem sucedidas, acreditamos ser necessário mapear a situação de gênero nos cursos da área de informática. Nesse sentido, quantificar estudantes dos gêneros masculino e feminino matriculados em cursos de TI, bem como analisar seus índices de aproveitamento acadêmico e evasão, são ações fundamentais para que possamos efetivamente compreender a inserção feminina nas áreas profissionais de informática em nosso país.

\section{Considerações finais}

As atividades de empoderamento feminino apresentadas neste trabalho são parte integrante da metodologia do projeto, sob a ótica da permanência das meninas nos cursos de Tecnologia da Informação. Com os primeiros resultados positivos, obtidos após a aplicação de questionários referentes às ações concluídas, pretende-se prosseguir com as atividades em prol de resultados mais concisos e um acompanhamento constante dessas estudantes. Ressaltamos que todas as referidas ações vêm sendo desenvolvidas localmente, através de projetos de pesquisa e extensão, que contam com a participação de alunas do curso Técnico em Informática para Internet Integrado ao Ensino Médio, e estudantes do curso de bacharelado em Sistemas de Informação.

Em nossa perspectiva, a visibilidade nestes dois níveis escolares pode contribuir tanto para alterar o quadro de evasão escolar feminina nos cursos ligados à informática, quanto para estimular maior inserção no mercado de trabalho em TI, possibilitando assim a multiplicação dessas ações, inclusive através das redes sociais, a fim de que outras jovens sintam-se motivadas em suas carreiras profissionais.

\section{Referências}

Castro, B. (2013) "Os gargalos para o ingresso e a permanência das mulheres no mercado de TI no Brasil", In: XII Conferencia Regional sobre la Mujer de la America Latina y Caribe.

Leta, J. (2003) "As mulheres na ciências brasileira: crescimento, contrastes e um perfil de sucesso", Estudos Avançados, São Paulo, v. 17, n. 49, p. 271-284.

Pisa em foco (2015) “O que está por trás da desigualdade de gênero na educação?”, https://www.oecd.org/pisa/pisaproducts/pisainfocus/PIF-49\%20(por).pdf, Março.

Russel, B. et al. (1979) “O poder: uma nova análise social”, Rio de Janeiro, RJ: Zahar.

Sales, A. S. et al. (2014) "Dificuldades para o ingresso e permanência na ciência e engenharia da computação: um olhar feminino", In: 18 REDOR.

Schiebinger, L. (2001) “O feminismo mudou a ciência?”, Bauru, SP: Edusc, 1ª edição.

Schwartz, J. et al. (2006) "Mulheres na informática: quais foram as pioneiras?", http://www.scielo.br/pdf/cpa/n27/32144.pdf, Março.

Soares, T. A. (2001) "Mulheres em ciência e tecnologia: ascensão limitada", Química Nova, São Paulo, v. 24, n. 2, p. 281-285. 